\title{
Ice Growth Acceleration by Antifreeze Proteins Leads to Higher Thermal Hysteresis Activity
}

Jinzi Deng, Elana Apfelbaum and Ran Drori*

Department of Chemistry and Biochemistry, Yeshiva University, New York, NY 10016, USA

\section{Supporting information}

1. Table S1 - Details of AF(G)Ps tested in this study.

2. Table S2 - fitting constants $\alpha$ and $\beta$ for each protein.

Table S1 - AF(G)Ps tested in this study.

\begin{tabular}{|c|c|c|c|c|c|}
\hline Protein & Structure & $\begin{array}{c}\text { MW } \\
\text { (kDa) }\end{array}$ & Origin & Binding Planes & $\begin{array}{c}\text { Effect of } \\
\text { concentration } \\
\text { on ice growth } \\
\text { velocity along } \\
\text { the } c \text {-axis }\end{array}$ \\
\hline AFP I & aroradar & 3.3 & $\begin{array}{l}\text { Winter Flounder } \\
\text { (Pseudopleuronectes } \\
\text { americanus) }\end{array}$ & Pyramidal & $\boldsymbol{A}$ \\
\hline $\begin{array}{l}\text { AFPIII- } \\
\text { QAE }\end{array}$ & & 7 & $\begin{array}{l}\text { Ocean pout } \\
\text { (Zoarces } \\
\text { americanus) }\end{array}$ & $\begin{array}{l}\text { Pyramidal and } \\
\text { prism }\end{array}$ & 4 \\
\hline LpAFP & & 13.5 & $\begin{array}{l}\text { Rye grass (Lolium } \\
\text { perenne) }\end{array}$ & Basal and prism & \\
\hline
\end{tabular}




\begin{tabular}{|c|c|c|c|c|c|}
\hline Protein & Structure & $\begin{array}{l}\text { MW } \\
\text { (kDa) }\end{array}$ & Origin & Binding Planes & $\begin{array}{l}\text { Effect on ice } \\
\text { growth } \\
\text { velocity along } \\
\text { the } c \text {-axis } \\
\text { with } \\
\text { increasing } \\
\text { concentration }\end{array}$ \\
\hline $\mathrm{AFPGP}_{8}$ & 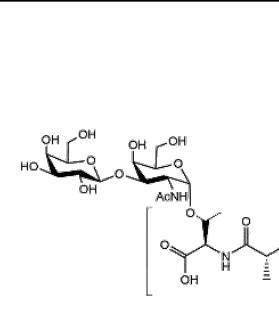 & $\begin{array}{c}2.6(4 \\
\text { repeats } \\
\text { of the } \\
\text { sequence } \\
\text { on the } \\
\text { left) }\end{array}$ & $\begin{array}{l}\text { Antarctic toothfish } \\
\text { Dissostichus } \\
\text { mawsoni }\end{array}$ & Prism & $\begin{array}{l}\text { No clear } \\
\text { effect }\end{array}$ \\
\hline $\mathrm{AFGP}_{2,3,4}$ & $\underbrace{\mathrm{OH}}_{\mathrm{OH}} \mathrm{O}^{\mathrm{OH}}$ & $\begin{array}{c}17-28.8 \\
(26-44 \\
\text { repeats } \\
\text { of the } \\
\text { sequence } \\
\text { on the } \\
\text { left) }\end{array}$ & $\begin{array}{l}\text { Antarctic toothfish } \\
\text { Dissostichus } \\
\text { mawsoni }\end{array}$ & Prism & $\begin{array}{l}\text { No clear } \\
\text { effect }\end{array}$ \\
\hline
\end{tabular}


Table S2 - fitting constants $\alpha$ and $\beta$ for each protein.

\begin{tabular}{|c|c|c|c|}
\hline \multirow{2}{*}{$\mathbf{A F P}$} & $\begin{array}{c}\text { Concentration } \\
(\mathbf{m g} / \mathbf{m l})\end{array}$ & $\boldsymbol{\alpha}(\boldsymbol{\mu \mathbf { m }} / \mathbf{s})$ & $\boldsymbol{\beta}\left({ }^{\mathbf{o}} \mathbf{C}\right)$ \\
\hline \multirow{3}{*}{$\mathrm{AFGP}_{8}$} & 1 & 573.63 & 0.363 \\
\cline { 2 - 4 } & 3 & 667.87 & 0.436 \\
\hline \multirow{2}{*}{$\mathrm{AFGP}_{2,3,4}$} & 0.5 & 556.17 & 0.300 \\
\cline { 2 - 4 } & 1 & 1184.98 & 0.379 \\
\hline \multirow{3}{*}{ AFPI } & 2 & 147.51 & 0.675 \\
\cline { 2 - 4 } & 4 & 49.41 & 0.461 \\
\hline \multirow{3}{*}{ AFPIII-QAE } & 6.5 & 717.41 & 0.774 \\
\cline { 2 - 4 } & 0.1 & 50.90 & 0.454 \\
\cline { 2 - 4 } & 0.3 & 96.57 & 0.498 \\
\hline \multirow{2}{*}{ LpAFP } & 0.5 & 188.99 & 0.558 \\
\cline { 2 - 4 } & 0.5 & 0.31 & 0.354 \\
\hline
\end{tabular}

